\title{
China and South Korea Diplomatic Relations - Present Status and Perspectives
}

\author{
Yongmei Li \\ Graduate School of International Studies, Yonsei University, Seoul, South Korea \\ E-mail: yongmei6@naver.com
}

\begin{abstract}
This study aims to discuss China and South Korea current well built strategic relationship and research the development direction of future diplomatic relations. The theoretical frame of this paper is to study two countries' strengthened cooperation on trade and business partnership. Further, some political conflicts and position are also discussed in detail. However, through analyzing each nations' concerns and interest, two countries' cooperation has more advantages than disadvantages. In a word, significant meaning of diplomatic relations between China and South Korea will benefit not only to two nations but also to East Asia, and even to the whole world.

Keywords: China, South Korea, diplomatic relations, present status, perspectives, cooperation, mutual interest, win-win strategy
\end{abstract}

\section{Introduction}

It has been 23 years since South Korea established diplomatic relations with China in 1992, and the outward and qualitative changes made within these 20 years are beyond imagination. South Korea and China established diplomatic relations officially on August 24, 1992, during which the relationship between China and South Korea was affirmed as "a good-neighborly and friendly cooperative relation". After that, Kim Dae-Jung, the Former President of South Korea visited China in November 1998. During the summit with Jiang Zemin, the President of China, the two parties decided to develop the relationship between the two countries into "the partnership of the 21st century" [1]. Roh Mu-Hyun, the President of South Korea held summits with Hu Jintao, the President of China and concluded the agreement of "comprehensive partnership", in respect of the relationship of the two countries while visiting China in July 2003. After that, as Lee Myung-bak Government came to power in May 2008, President Lee Myung-bak held summits with President Hu Jintao while he visited China, and promoted the relationship of the two countries from "comprehensive partnership" to "strategic partnership".

Besides, China has also converted its defensive policies into offensive policies in diplomacy ${ }^{[2]}$. Therefore, the growth of China and its changes in policy tones form a new phase for the diplomacy with South Korea. Although China and South Korea have concluded an agreement, in respect of establishing major "strategic partnership" between the two countries, there are still fuzzy factors about the concept of "strategic partnership", and huge confusions in the understanding about the property and development direction of China and South Korea relations. With the upcoming diplomatic cooperation between China and South Korea, it is expected to include topics that should be overcome for the peaceful development of China and South Korea, and analyze the plans for China and South Korea to cope with diplomatic relations actively, which is the motivation and objective to write this paper.

\subsection{Research methods and compositions}

With respect to the research method, this paper mainly uses literature research and comparative analysis method for research. Therefore, it will classify all types of partnerships and strategic relations signed by China, and carry out comparative analysis on its contents and future topics, etc., understand the position of all partnerships in Chinese diplomacy and Chinese strategic intent, and obtain the implication and enlightenment to Korea.

In this paper, it adopts document research method, and will combine the first-hand data analysis and second-hand data analysis for research. Analysis is carried out by regarding the collected official joint statement, historical references and published statistical data as the first-hand data, and the data related to the research achievements of current partnership diplomacy or strategic relations as the second-hand data. On this basis, this paper will classify and sort out countries that have established partnership with China so far, especially for strategic partnerships comprehensively promoted since the 21 st century. By sorting out and analyzing literatures related to current partner diplomacy in China, this paper analyzes the strategic implication of partnership after the medium term of 1990s, the officially promoted partner diplomacy as well as 
the contents and positions of core strategic partnerships as partner diplomacy is reinforced and expanded qualitatively after 2000 .

Besides, the current research and analysis contents will be further analyzed and perfected in details based on the method of comparative analysis. In a manner of speaking, the essence of research in comparative analysis is the concept that comparative unit hypothesis. Concept is the final product of scientific research, i.e., the basic constitutive element of rules, so we can say that theoretical work is started from the construction of concepts.

\subsection{Discussion about prior studies}

Previous studies about China and South Korea "strategic partnership" emphasize on the intention or positive layer of South Korea, but in fact, less attention is paid to the current problems and topics to be solved in China and South Korea relations. Besides, the characteristic is to focus on Chinese partner diplomacy and strategic partnership, and then sort out and analyze original research literatures. Characteristics of original studies are as follows.

Previous researches lack in comparative researches between countries of strategic partnership as well as the horizontal comparison with state groups of the same type with South Korea in Chinese diplomacy, so there can be certain limitations. There are relevant studies in South Korea to analyze the understandings about Chinese partner diplomacy. are there any set boundaries of strategic partnership in the domestic researches of South Korea? In fact, this has also made the analysis on the meaning and topic of China and South Korea relations insufficient.

\section{Present status of China and South Korea diplomatic relations}

China and South Korea published Joint Declaration on August 24, 1992, ended decades of isolations in the past and officially established diplomatic relations ${ }^{[3]}$. After that, the two countries' relations advanced rapidly, and the development of policies, economies, society, culture and military, and other major fields can be described as "a miracle throughout diplomatic history". Since the establishment of diplomatic relation in 1992, China and South Korea relations have went well without big frictions, except for issues related to North Korean defectors. The first crisis for China and South Korea relation is the so-called "garlic dispute" era occurred in 2000. China has been the biggest trading country of South Korea ${ }^{[4]}$. In the first year of establishing the diplomatic relation, trading volume between South Korea and China reached up to USD 6.38 billion (according to the statistics of Korea Foreign Trade Association). Besides, according to statistics at year-end 2009, the export amount of China to South Korea was USD 54.2 billion, while the export amount of Korea to China was USD 86.7 billion, and the total trading amount reached to USD 140.9 billion, which was increased by 22 times in 18 years. The trading amount reached to $20.5 \%$ of the total trading amount in Korea, which was more than the sum of USD 71.2 billion trading amount between South Korea and Japan and USD 66.7 billion trading amount between South Korea and America. Besides, the trade surplus of South Korea for China was USD 32 billion, which was also a peak value. According to the estimation of South Korean Government, the trading scale between China and South Korea would reach to USD 200 billion in 2012, and USD 300 billion in 2015. Since South Korea has an economic structure of external dependence, China is more important to it than any other countries.

President Hu Jintao officially visited South Korea in November 2005, expanded China and South Korea relations into the cooperation in policies, economics, society, culture, and military, etc. solved North Korean nuclear issues in peace, carried out cooperation of China, South Korea and Japan, decided to closely promote regional cooperation in East Asia Summit (EAS), Association of Southeast Asian Nations Regional Forum (ARF), Asia-Pacific Economic Cooperation (APEC), Asia-Europe Meeting (ASEM) during the summits held with President Roh Mu-Hyun, and by signing Memorandum of Understanding About Expanding China And South Korea Trade Investment Cooperation and Memorandum of Understanding About International Cooperation of Trade between China and South Korea, and Korea recognized the market economy status (MES) of China. Li Huaiyu said in Research on Chinese National Strategies, "in the development of comprehensive partnership, the two countries expanded cooperation level comprehensively in policies, diplomacy, military, security, economics, trade, society and culture, and seek for the cooperation of the two countries, to solve North Korean nuclear issues, and also start to promote cooperation in regional problems." ${ }^{[5]}$

China and South Korea relations was changed to "comprehensive partnership" from "partnership" and "friendly cooperative partnership" and then promoted to strategic partnership in 23 years, and we can see the glories achievements for the development of China and South Korea relations. As can be seen from the 23-year history since the diplomatic relation was established, the development of China and South Korea relations is a miracle. Being driven by the fast development of relations between the two countries, the strategic partnership established between the two countries indicates that China and South Korea have become partners that can jointly discuss about the localization, global multi- 
lateral problems as well as long and medium-term focus issues, in respect of relations of the two countries.

\subsection{Conflicts in China and South Korea diplomatic relations}

The problem is that the standpoint of the two countries is now changing with the economic growth in China. Although China is the biggest trading nation of South Korea, South Korea is competing against China in lots of the same fields, or can be regarded as in a phase that can look down on China than ever before.

Zhang Zhongning shows in Comparative Research on the Strategy of Free Trade Zones between China and the United States, "there have also been worries about the rise of China in South Korea based on the condition that various major products produced by South Korea have been surpassed by China in overseas market" ${ }^{[6]}$. Except that, more and more people are worrying that South Korean dependency on Chinese trade is now increasing fast, and they think that China threats the safety of South Korea. The result investigated by Private Public Opinion Investigation Authority, "NI South Korea" among above 1,000 South Korean adults in March 2006 upon the entrustment of KIDA is as shown below. Speaking of the country that will cause the biggest threat to the safety of South Korea in the next decade, China was regarded as that country by $37.7 \%$ interviewees, followed by Japan, North Korea, and America by $23.6 \%, 20.7 \%$ and $14.8 \%$ interviewees respectively, which means that, South Korean fear of China because of our fast economic growth and reinforced military forces.

Table 1. 1985-2009 South Korean Trading Dependency on China

\begin{tabular}{cc}
\hline Year & Ratio of China trade in the total trading volume of South Korea (\%) \\
\hline 1985 & 1.9 \\
1990 & 2.8 \\
1995 & 6.4 \\
2000 & 9.4 \\
2003 & 15.3 \\
2007 & 19.8 \\
2009 & 20.5 \\
\hline
\end{tabular}

As can be seen from the table, South Korean trading dependency on China was increased to $20.5 \%$ in 2009 from $1.9 \%$ in 1985, and the ratio of export to China in the total export of South Korea was increased to $22 \%$ in 2007. If we considered that the trading dependency of China for South Korea was merely $6.4 \%$ in 2009, the expansion of relative difference in dependency will be gradually expanded "China threat theory" in South Korea.

First of all, South Korea felt unsecure about Chinese security based on its history. South Korea started to mobilize the Academy of Social Sciences and three provinces in the northeast of China since 2002, incorporate histories of Koguryo and Bohai Sea into the history of South Korea, and recover cultural relics scattered in Manchu correspondingly. Except that, it is believed by South Korea that all of them are Koguryo culture. For South Korean, it is natural that they can feel unsecure about the actions of China as its comparable and neighbor country in both military and economy ${ }^{[7]}$.

There are conflicts in the successful development of China and South Korea relations, and except for disputes over Koguryo histories, there were also other events, including the conflicts between China and Korea over the application of regions (Beakdu Mountain $<$ Changbai Mountain $>$ ) and traditional culture (Gangneung Danoje Festival $<$ Dragon Boat Festival $>$ ) to UNESCO for major world's culture heritage. There was also frequent occurrence of disputes over territorial waters and territorial skies. Besides, China was also accused of causing serious environmental problems to Korean Peninsula, especially the air pollution caused by sulfur dioxide. The concerns and worries of issues related to North Korean defectors are also one of the major reasons why South Korean political elites are cautious of China. Because South Korean Government held that this was an issue of human rights, while China criticized that this is a violation of sovereignty. In this regard, many elites showed disagreement in normative layer, but South Korea held that North Korea is the most serious obstacle factor in China and South Korea relations ${ }^{[8]}$.

The serious problem faced by China in the successful development of China and South Korea relations is America and South Korea joint military drill and Taiwan problems. China responded strongly to America and South Korea joint military drill, because of Chinese value on sovereignty and territory, while Western Sea military drill made China feel stressed to some extent. Besides, the only objection against the endeavors made by South Korea to improve the relations with China is from Taiwan which was officially recognized by South Korea as Chinese Government. Taiwan had the same worries with North Korea, i.e., as China and South Korea relations are normalized, they will lose the core friendly nation against the 
mainland of China, so they have been focusing on the improvement process of China and South Korea relations.

\subsection{Diplomatic decisions made by South Korea}

Yang Xumeng shows in Korean Peninsula Crisis and Sino-US Relations,"to some extent, instead of saying that South Korea thinks that China is friendly, you can say that after 2000, South Korea has constantly changed and evolved its recognition on China. Currently, the problem faced by South Korea is to make a choice between the variations in America and China" ${ }^{[9]}$.

Although South Korean showed dual character and worries in the recognition of China, it should be noticed that political elites in South Korea experienced certain changes in the recognition of China, according to the result of an investigation made by an American think tank oriented to the leading groups of new public opinions in South Korea in $2002,86 \%$ interviewees expected to reinforce the relations with China, while merely $14 \%$ interviewees chose to reinforce the relations with America. Besides, Li Guitai wrote in Theory of Modernized South Korea and China Relations, "according to the questionnaire oriented to 138 primary congress members abroad in 2004 (68\% Open Nationalist Party members and $43 \%$ Grand National Party members), 55\% interviewees answered that China is a diplomacy object more important than America" ${ }^{[10]}$. According to another investigation in May of the same year, merely 33\% Grand National Party members held that China is more important, and 63\% Open Nationalist Party members valued China more, which can highlight the difference of the two political parties. "In the investigation about congress candidates dated in 2008, most members of Grand National Party advocated "to recover the alliance relations between South Korea and America", while Democratic Party members expressed "to promote diversified diplomatic routes", which can highlight the difference of different political parties in the favor of relations with China, i.e., China has become the core variation influencing the relation between South Korea and America and the major political problem to be solved by South Korea.

The national power of North Korea had been suppressing South Korea in 1950s-1960s, with big military threat, so South Korea had to accept America to survive, during which this wasn't an issue to be balanced for South Korea considering whether to form alliance. From the standpoint of South Korea with weaker economic strength, it needed to seek for "external balancing" by forming alliance with America, even if it would weaken its sovereignty, when comparing with the reinforcement of "internal balancing" for autonomous defense capability, with no other choices. Since America adopted "benign neglect" policy that won't cause big problems when providing large-scaled assistance to South Korea, South Korea and America relations developed fast ${ }^{[11]}$.

Just like America as the major diplomacy country of security and economy, China is also a super power for Korean Peninsula. Therefore, this has also highlighted the necessity for South Korea to reinforce the diplomacy to China. In order to keep a good relationship between China and Korea, South Korea should give priority to the peace and stability of Korean Peninsula, in respect of the highest policies.

China will act in the same way of supporting "parties' priority" between South Korea and North Korea ${ }^{[12]}$. In the meantime, comparing to unilaterally following American hegemony, South Korea should be more cautious to explore the effect of balancers for East Asian powers. It may be more urgent to promote new coordination work for strategic stake of South Korea, America and China when this process becomes stable. For South Korea, it should be equipped with comprehensive diplomacy wisdom to give full consideration to both America and China in the same time.

While exploring new conceptions for the cooperation of the East Asian region, the core tension factor to be eliminated in the region should be Korean Peninsula peace and cooperation. The solution of Korean Peninsula is closely related to the new regional development mode and economic development strategies in East Asia. Under such conditions, it's an important task to adhere to the same keynote of market economy with China, and deepen the negotiation framework in all aspects. Meanwhile, as the major friendly nation of North Korea, China values market economy, which will also be quite meaningful to South Korea.

\section{Outlook of China and South Korea diplomatic relations}

We would welcome the 23rd Anniversary for the Establishment of China and South Korea Diplomatic Relations in August 2015. China has become an important country for South Korea in safety, economy, culture, etc. Besides, since China is its neighbor country in geological location, this requests South Korea to have a new recognition on China, as China's economy develops fast. Especially because of the nationalistic tendency, South Korea is a country that China should get close to, but this process can be quite difficult. Besides, the special relations between China and North Korea must be considered while handling issues related to the Korean Peninsula ${ }^{[13]}$.

Up till 2007, the word "comprehensive partnership" used to describe South Korea and China relations had represented 
a feature close to symbiosis. However, in consideration of the huge influence caused by unbalanced forces in international policies, if South Korea cannot give full play to different diplomatic forces, whether the symbiotic relation can sustain will largely depend on the will of China ${ }^{[14]}$. Li Donglv expressed in the Diplomatic Strategies and Objectives of Chinese Surrounding Regions, "Chinese influence on South Korea is getting bigger, and in case of being restricted by the desire to improve the national dignity and position of the country, symbiotic relation of the two countries may be degraded to "cohabitation" phase at any time." "15]

South Korea should also consider converting from the phase of merely having a good impression on China to the phase of reflecting on which country is more friendly and tolerant to South Korea, America or China. This is to say that, in comparison with the rising process of China, it is worthy of noticing whether the kind opinions and expectations of South Korean for China will last longer.

\section{Summary}

In Chinese diplomacy, strategic partnership refers to recognizing the mutual interest. China and South Korea "strategic partnership" will be gradually realized based on the cooperation contents agreed by the two countries. China and South Korea established the future strategic development direction by establishing the relation based on fully recognizing the importance of the opposite country. Therefore, the development of relations between China and South Korea as well as the peace and prosperity of Northeast Asian region are closely related to the confirmation of "strategic partnership" contents and how to promote the process.

China and South Korea "strategic partnership" shall be equipped with the following significance. Firstly, China and South Korea should promote mutual cooperation to a strategic level for the joint long-term objective of peace and prosperity. Secondly, the cooperation of the two countries shouldn't be restricted to bilateral problems, and should be expanded towards regional and global levels comprehensively. Thirdly, it is requested to promote mutual cooperation in regional and global problems, and expand strategic partnership.

With respect to China and South Korea strategic partnership, firstly, we can find out the significance to promote as strategic relations. In the meantime, the future topics are still related to what kind of strategies to build, and what kind of new relations to establish based on this strategy. Besides, agreements have also been concluded, in respect of setting "partnership". Therefore, the first thing is to reinforce mutual trust in the future China and South Korea relations, and it is extremely necessary to make constant endeavors to expand the joint interests of China and South Korea, and promote the relations to a new phase. 


\section{References}

[1] Li Xiyu. Topics and Exploration Plans for South Korea and China Relations in the $21^{\text {st }}$ Century. Beijing: Social Sciences Academic Publishing; 2008.

[2] Pang Zhongying. Asia: Strategic Emphasis of Chinese External Policies. Beijing: Social Sciences Academic Publishing; 2001.

[3] Wang Sheng. 15 Years since the Establishment of China and South Korea Diplomatic Relations: A Miracle throughout Diplomatic History, and a Model of Peaceful Coexistence. Beijing: Beijing Social Sciences Academic Publishing; 2007.

[4] Piao Jianyi, Piao Guangji. China and South Korea Relations and Northeast Asian Economic Community. Beijing: China Social Sciences Publishing; 2006.

[5] Li Huaiyu. Research on Chinese National Strategies. Seoul: Politeia Publishing; 2007.

[6] Zhang Zhongning. A Comparative Study on the Strategy of Free Trade Zones between China and the United States. University of International Business and Economics. 2018.

[7] Tang Shiping. Building an Ideal Security Environment in China. Beijing: China Social Sciences Publishing; 2003.

[8] Cui Minghai. China-North Korea ASEAN Relations: Inconvenient Cohabitation History. Seoul: Orum Publishing; 2009.

[9] Yang Xumeng. The Korean Peninsula Crisis and Sino-US Relations. CPC Central Party School. 2004.

[10] Li Guitai. Theory of Modernized South Korea and China Relations. Seoul: BumHanBook Publishing; 2007.

[11] Zhang Xiaoming. Analysis on Chinese Surrounding Security Environment. Beijing: China International Broadcast Publishing; 2003.

[12] Zhao Huasheng. China's Central Asian Diplomacy. Beijing: Current Affairs Publishing; 2008.

[13] Zhang Yunling. China and Surrounding Countries: Build New Partnership. Beijing: Social Sciences Academic Publishing; 1997.

[14] Zhang Yushan. Retrospect and Outlook of Comprehensive Partnership between China and South Korea. Beijing: Peking University Publishing; 2007.

[15] Li Donglv. Diplomatic Strategies and Objectives of Chinese Surrounding Regions. Chinese Studies. 2006. 